\title{
World Health Organization (WHO) antibiotic regimen against other regimens for the treatment of leprosy: a systematic review and meta-analysis
}

Maria Lazo-Porras ${ }^{1,2+}$, Gabriela J. Prutsky ${ }^{1,3+}$, Patricia Barrionuevo ${ }^{1}$, Jose Carlos Tapia ${ }^{1,10}$, Cesar Ugarte-Gil ${ }^{4,9,11}$, Oscar J. Ponce ${ }^{1}$, Ana Acuña-Villaorduña 1,5, Juan Pablo Domecq ${ }^{1,6}$, Celso De la Cruz-Luque ${ }^{1,7}$, Larry J. Prokop ${ }^{8}$ and Germán Málaga ${ }^{1,9^{*}}$ (i)

\begin{abstract}
Background: To evaluate the effectiveness and safety of the World Health Organization antibiotic regimen for the treatment of paucibacillary (PB) and multibacillary (MB) leprosy compared to other available regimens.

Methods: We performed a search from 1982 to July 2018 without language restriction. We included randomized controlled trials, quasi-randomized trials, and comparative observational studies (cohorts and case-control studies) that enrolled patients of any age with PB or MB leprosy that were treated with any of the leprosy antibiotic regimens established by the WHO in 1982 and used any other antimicrobial regimen as a controller. Primary efficacy outcomes included: complete clinical cure, clinical improvement of the lesions, relapse rate, treatment failure. Data were pooled using a random effects model to estimate the treatment effects reported as relative risk (RR) with 95\% confidence intervals (Cl).

Results: We found 25 eligible studies, 11 evaluated patients with paucibacillary leprosy, while 13 evaluated patients with MB leprosy and 1 evaluated patients of both groups. Diverse regimen treatments and outcomes were studied. Complete cure at 6 months of multidrug therapy (MDT) in comparison to rifampin-ofloxacin-minocycline (ROM) found RR of 1.06 (95\% Cl 0.88-1.27) in five studies. Whereas six studies compare the same outcome at different follow up periods between 6 months and 5 years, according to the analysis ROM was not better than MDT (RR of 1.01 (95\% Cl 0.78-1.31)) in PB leprosy.
\end{abstract}

Conclusion: Not better treatment than the implemented by the WHO was found. Diverse outcome and treatment regimens were studied, more statements to standardized the measurements of outcomes are needed.

Keywords: Leprosy, Treatment, Systematic review, World Health Organization

\footnotetext{
*Correspondence: gmalaga01@gmail.com

${ }^{\dagger}$ Maria Lazo-Porras and Gabriela J. Prutsky are joint first authors

"CONEVID Unidad de Conocimiento y Evidencia, School of Medicine "Alberto

Hurtado", Universidad Peruana Cayetano Heredia, Av. Honorio Delgado 430,

Lima 31, Peru

'School of Medicine "Alberto Hurtado", Universidad Peruana Cayetano

Heredia, Lima, Peru

Full list of author information is available at the end of the article
}

(c) The Author(s). 2020 Open Access This article is distributed under the terms of the Creative Commons Attribution 4.0 International License (http://creativecommons.org/licenses/by/4.0/), which permits unrestricted use, distribution, and reproduction in any medium, provided you give appropriate credit to the original author(s) and the source, provide a link to the Creative Commons license, and indicate if changes were made. The Creative Commons Public Domain Dedication waiver (http://creativecommons.org/publicdomain/zero/1.0/) applies to the data made available in this article, unless otherwise stated. 


\section{Background}

Leprosy is a neglected disease caused by Mycobacterium leprae that affects the skin and peripheral nerves. Although treatment exists, access is limited and if it is not initiated early in the course of the disease, the control is suboptimal and permanent disabling sequelae can occur [1]. On the other hand, research on leprosy is scarce, limiting the development of new strategies. Additionally, in the general population leprosy is feared and misunderstood. Patients, who suffer this disease, since biblical times, are victims of ostracism, stigma and neglect in many cases [2].

Even when the prevalence of this disease has significantly decreased, and most previously highly endemic countries have reached erradication (defined as a registered prevalence rate of $<1$ case/10000 population), it continues to be a global health concern [3]. In 2014, the World Health Organization (WHO) estimated that 213,899 new patients were diagnosed globally. Most of them come from developing countries such as Brazil, India and Indonesia. These nations accounted for $81 \%$ of new cases [4].

The best treatment regimen available continues to be controversial with limited evidence support. In 1981, the WHO developed, by consensus, a multidrug therapy (MDT) with dapsone and rifampin for 6 to 12 months for paucibacillary $(\mathrm{PB})$ while clofazimine was added and the length of therapy extended to 24 months for multibacillary (MB) leprosy [5]. These recommendations were reformulated in 1998, reducing the treatment duration to 6 and 12 months respectively, mainly based on economic reasons [6]. On the other hand, the National Hansen's Diseases Programs (NHDP) in Peru continues to favors a longer duration of therapy [7]. Recently, other drugs as minocycline, ofloxacin, levofloxacin, clarithromycin and moxifloxacin have shown to be effective against $M$. leprae [8].

Considering the lack of an accurate quantitative endpoint (noncultivable pathogen), and a very long observation period for identification of relapse (approximately 15 to 20 years), conducting a trial to compare antibiotic regimens in this disease results extremely difficult, leading to a weakness and lack of evidence. Therefore, we conducted a systematic review to evaluate the effectiveness and safety of the WHO antibiotic regimen for the treatment of $\mathrm{PB}$ and $\mathrm{MB}$ leprosy compared to other available regimens.

\section{Methods}

This review was reported following the Systematic Reviews and Meta-Analyses (PRISMA) guidelines [9].

\section{Eligibility criteria}

Following our predesign protocol we included randomized controlled trials (RCTs), quasi-randomized trials, and comparative observational studies (cohorts and case-control studies) that enrolled patients of any age with $\mathrm{PB}$ or MB leprosy who were treated with any of the leprosy antibiotic regimens established by the WHO in 1982 and used any other antimicrobial regimen as a controller.

\section{Information sources and search}

An experienced librarian (LJP) with expertise in conducting systematic reviews designed and conducted the electronic search strategy with input from the study investigators. We searched multiple electronic databases (Ovid Medline In-Process \& Other Non-Indexed Citations, Ovid MEDLINE, Ovid EMBASE, Ovid Cochrane Database of Systematic Reviews, Ovid Cochrane Central Register of Controlled Trials, Scopus, and LILACS) from 1982 to July 2018 without any language restriction. Controlled vocabulary supplemented with keywords was used to search for the topics of leprosy and WHO multidrug therapy (MDT), as well as to limit the search to randomized trials and observational studies conducted in humans. The detailed search strategy is listed in Additional file 1 . This search was complemented by a manual search that included, reviewing the reference lists of the eligible primary studies, narrative reviews and queried experts.

\section{Study selection}

Two independent reviewers screened all abstracts and titles and selected potentially eligible studies for full-text assessment. Disagreements were included during this phase. Upon retrieval of the full text version of potentially eligible studies, the review process was repeated using pre-defined eligibility criteria. Disagreements were resolved by consensus (reviewers discussed the study and reached a consensus); when this was not possible, by arbitration (a third reviewer). We achieved almost perfect agreement $(\mathrm{k}=0.9)$ during this phase.

\section{Data collection}

Data were extracted using a pre-designed, piloted extraction form. Working in duplicates and independently reviewers extracted the following variables from each study: study characteristics, baseline patient characteristics, intervention details, and outcomes of interest. Disagreements were resolved by consensus.

Primary efficacy outcomes included: 1) Complete clinical cure, defined as full regression of the lesions; 2) Clinical improvement of the lesions, defined by a clinical criteria; 3) Relapse rate, defined as the presence of the disease after completing the treatment (clinical or bacteriological or therapeutic criteria) [10]; 4) Treatment failure, defined as persistence or worsening of skin lesions and failure to improve the bacillary index for $\mathrm{MB}$ 
leprosy. Bacillary index (BI) improvement and neuritis were considered secondary efficacy outcomes. Neuritis was considered if participants reported pain during the interview or when participants complains of pain in one or more peripheral nerve trunks of the $\operatorname{limb}(\mathrm{s})$ during the period of the treatment.

Regarding safety outcome, we evaluated severe side effects (defined as a side effect that forced the patient to stop the treatment), and mild to moderate side effects. Also, we evaluated immunological reactions: type I (reverse reaction), and type II (erythema nodosum leprosorum - ENL).

\section{Author contact}

We contacted corresponding authors of each study twice within 2 weeks via e-mail or by phone or mail when email was not available if additional information was required.

\section{Quality assessment}

We used the Cochrane Collaboration's tool for assessing risk of bias [11] to evaluate the methodological quality of the included RCTs. This was assessed independently by duplicate for each study. For observational studies, we used the Newcastle-Ottawa Scale [12].
Statistical analysis and data synthesis

We summarized the qualitative data (eg. study population, design, intervention, comparison, outcomes) of the included studies in tables. If meta-analysis was appropriate, data was pooled using a random effects model to estimate the treatment effects reported as relative risk (RR) with 95\% confidence intervals (CI) [13] for dichotomous outcomes and mean difference (MD) or standardized mean difference (SDM) with 95\% CI for continuous outcomes. Statistical heterogeneity was assessed using $\mathrm{I}^{2}$ statistic [14]; $\mathrm{I}^{2}$ values over $50 \%$ indicated significant heterogeneity across studies' populations and interventions. In case data were insufficient for meta-analysis, a descriptive summary of the outcome findings was reported per categorization of type of leprosy ( $\mathrm{PB}$ and $\mathrm{MB})$. If the primary studies did not report standard deviations so they had to be inputted using the other studies as reference [15].

\section{Assessment of publication bias}

The assessment of publication bias was unfeasible due to the small number of trials [15].

\section{Results}

Search results and study description

The primary search strategy identified 480 references. After initial screening, 135 studies were eligible to full text screening. Finally, 25 studies (22 RCTs, a case-

\section{Potentially relevant studies identified by database sources and other sources $(\mathrm{N}=480)$}

\section{Articles selected for full text retrieval $(\mathrm{N}=135)$}

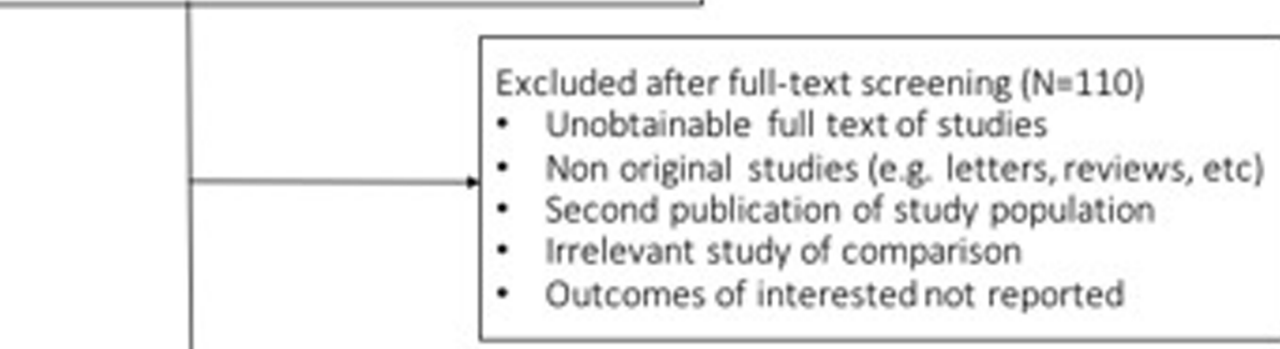

25 studies

Fig. 1 Flowchart of the study 


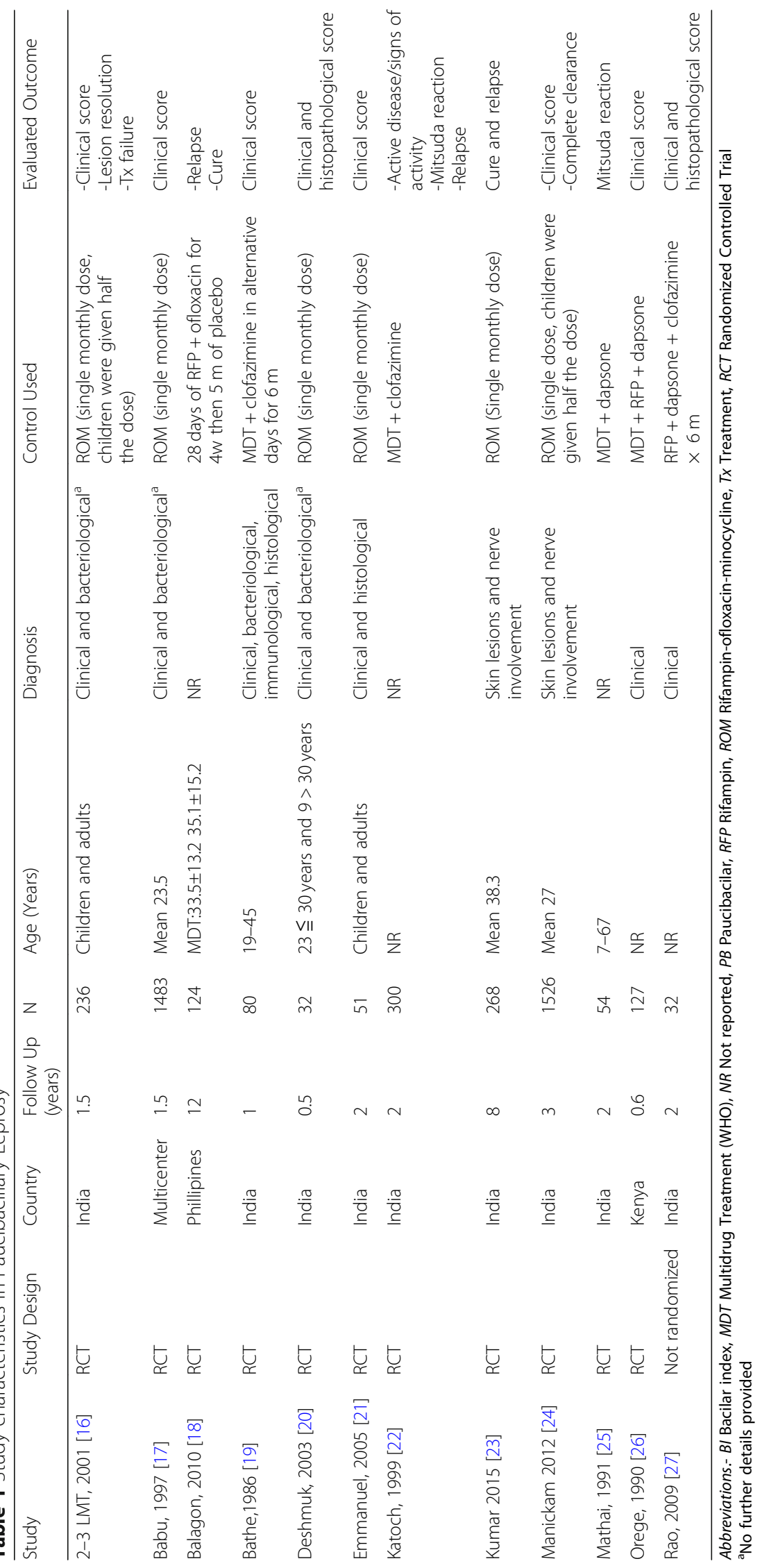




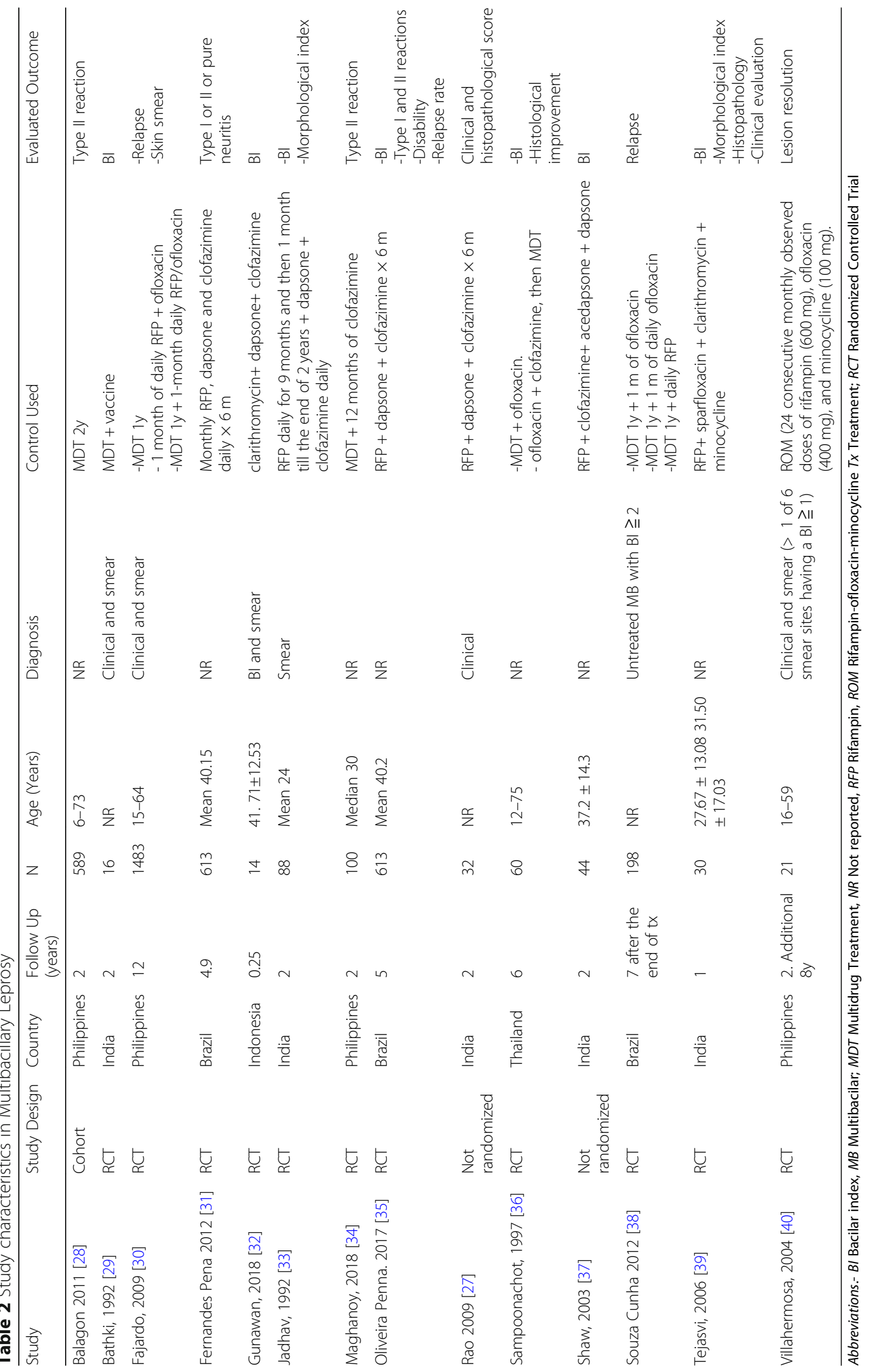




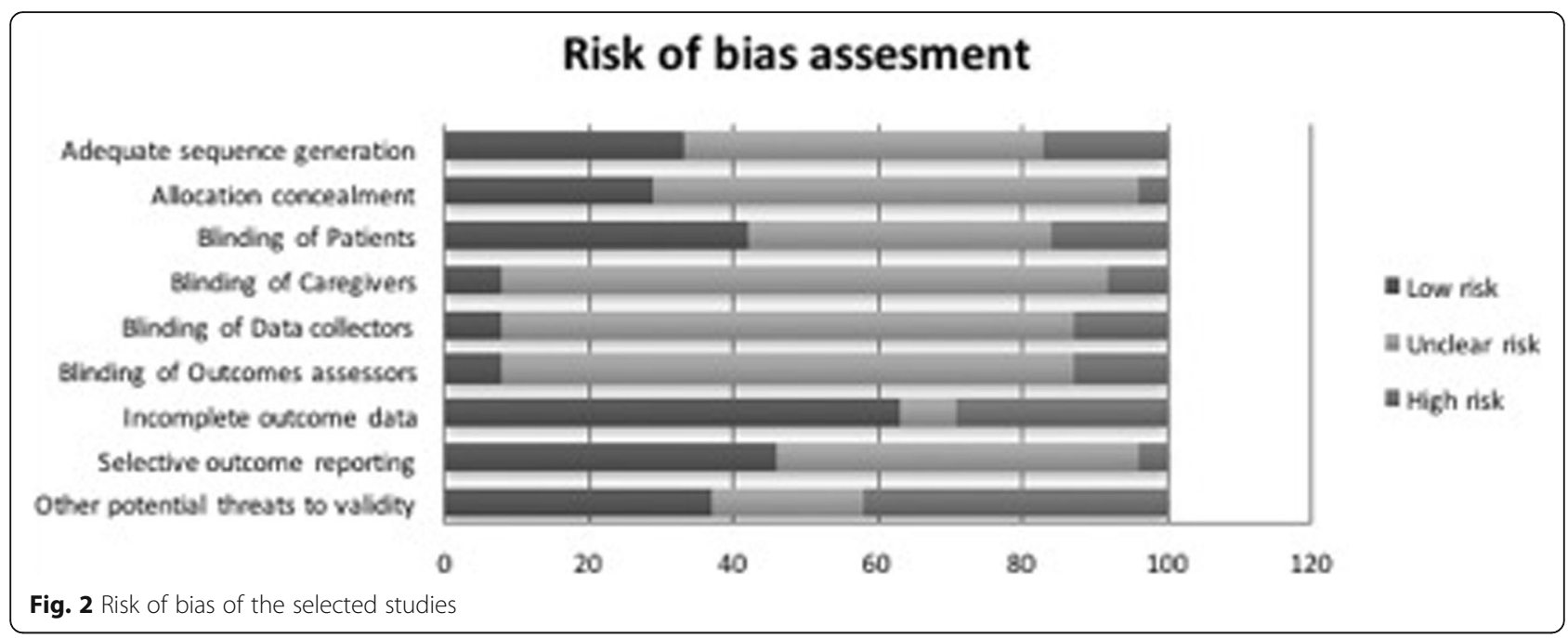

control study and 2 non-randomized trial) met our inclusion criteria and were included in our review (Fig. 1). One study does not have the full text available and we contacted the corresponding author without getting an answer. Also, another author was contacted to ask the author about the study design without a successful answer. No unpublished studies were identified.
The included studies (Tables 1 and 2) enrolled 8214 patients with a mean age of 35.2 years (range: 6 to 75 years). Eleven studies evaluated patients with PB leprosy (4281 patients), while 9 evaluated patients with MB leprosy (3869) patients) and 1 included patients from both groups. Follow up period ranged from 3 months to 12 years. All the studies were conducted in the developing

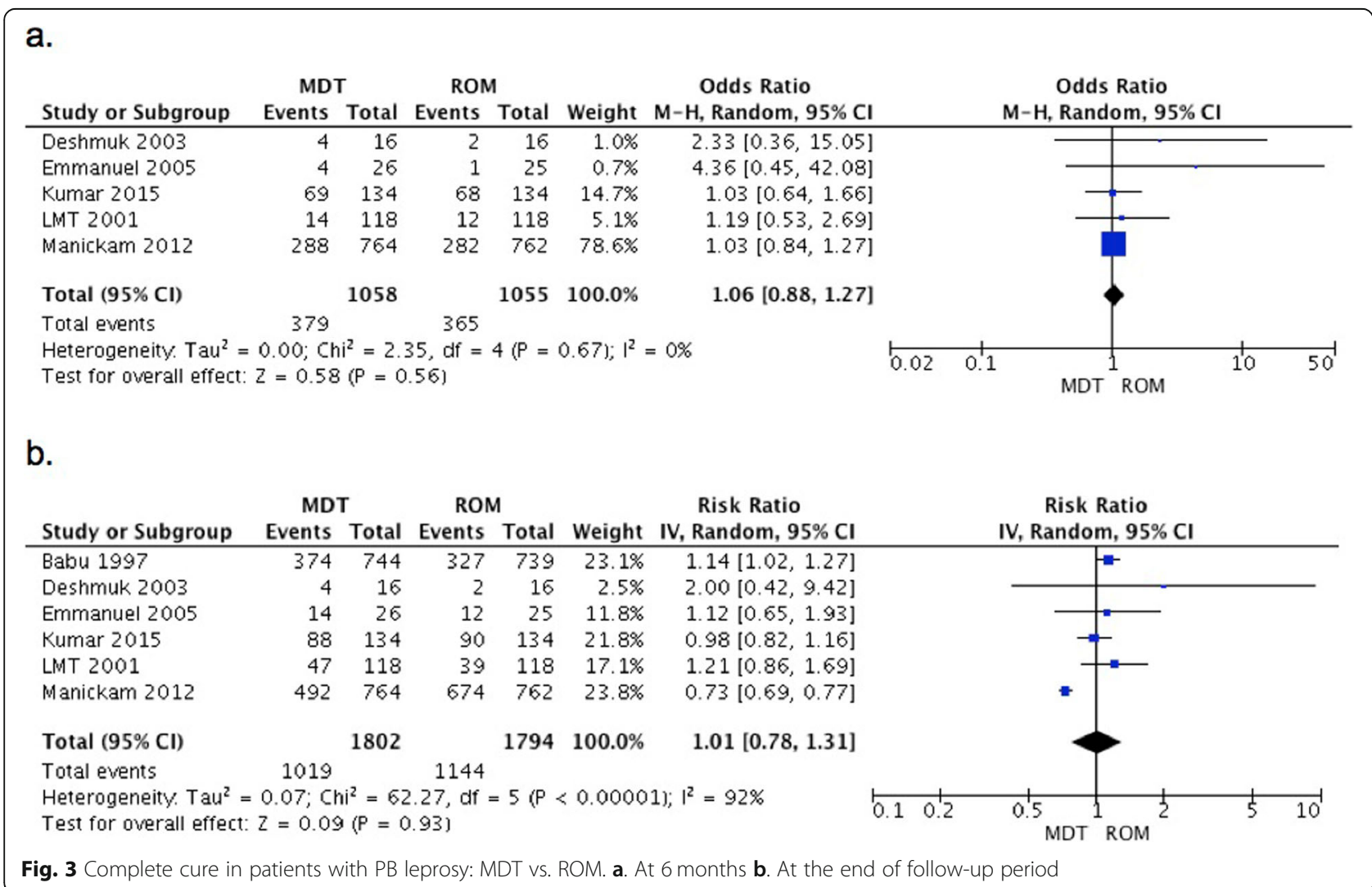


Table 3 Efficacy Outcomes

\begin{tabular}{|c|c|c|c|c|c|c|}
\hline \multicolumn{7}{|l|}{ Complete Clinical Cure } \\
\hline Study & Patients & Comparison & Follow up & $\mathrm{RR}$ & $95 \% \mathrm{Cl}$ & $p$ value \\
\hline \multirow[t]{2}{*}{ Balagon, 2010 [18] } & $\mathrm{PB}$ & MDT vs. 28 days of RFP + ofloxocin for $4 w$ then 5 months of placebo & $6 \mathrm{~m}$ & 4.2 & $2.25-7.85$ & $<0.05$ \\
\hline & & & $12 \mathrm{~m}$ & 0.93 & $0.80-1.09$ & 0.38 \\
\hline \multirow[t]{2}{*}{ Bathe, 1986 [19] } & & MDT vs. MDT+ clofazimine in alternative days for $6 \mathrm{~m}$ & $6 \mathrm{~m}$ & 1.25 & $0.77-2.04$ & 0.37 \\
\hline & & & $24 \mathrm{~m}$ & 1.09 & $0.93-1.27$ & 0.29 \\
\hline Orege, 1990 [26] & & MDT vs. Modified MDT (MDT + RFP + dapsone) ${ }^{a}$ & $6 \mathrm{~m}$ & 0.76 & $0.61-0.95$ & 0.02 \\
\hline \multicolumn{7}{|l|}{ Clinical Improvement } \\
\hline Study & Patients & Comparison & Follow up & MDT & Control & \\
\hline \multirow[t]{4}{*}{ Rao, 2009 [27] } & PB & MDT vs RFP + dapsone + clofazimine (good) & $24 \mathrm{~m}$ & $6 / 11(52 \%)$ & $7 / 9(78 \%)$ & \\
\hline & & MDT vs RFP + dapsone + clofazimine (moderate) & & $3 / 11(27 \%)$ & $2 / 9(22 \%)$ & \\
\hline & $\mathrm{MB}$ & MDT vs RFP + dapsone + clofazimine (good) & & 13/17 (77\%) & $1 / 4(25 \%)$ & \\
\hline & & MDT vs RFP + dapsone + clofazimine (moderate) & & $3 / 17(17 \%)$ & None & \\
\hline \multirow[t]{2}{*}{ Sampoonachut, 1997 [36] } & & MDT vs. MDT + ofloxacin. & $36 \mathrm{~m}$ & $66.70 \%$ & $73.30 \%$ & \\
\hline & & MDT vs. ofloxacin + clofazimine, then MDT & & $66.70 \%$ & $76.50 \%$ & \\
\hline Tejasvi, 2006 [39] & & MDT vs. RFP + Sparfloxacin + clarithromycin + minocycline & $12 \mathrm{~m}$ & $66.66 \%$ & $73.92 \%$ & \\
\hline Villahermosa, $2004[40]^{\mathrm{b}}$ & & MDT vs. ROM & $96 \mathrm{~m}$ & 22 points & 20 points & \\
\hline \multicolumn{7}{|l|}{ Relapse } \\
\hline Study & Patients & Comparison & Follow up & $\mathrm{RR}$ & $95 \% \mathrm{Cl}$ & $p$ value \\
\hline Balagon, $2010[18]$ & PB & MDT vs. 28 days of RFP + ofloxacin for $4 \mathrm{w}$ then $5 \mathrm{~m}$ of placebo & $12 \mathrm{~m}$ & 1.76 & $0.16-18.88$ & 0.64 \\
\hline Katoch, 1999 [22] & & MDT vs. MDT+ clofazimine & $24 \mathrm{~m}$ & 5 & $0.24-103.28$ & 0.3 \\
\hline \multirow[t]{2}{*}{ Kumar, 2015 [23] } & & MDT vs. ROM & $24 \mathrm{~m}$ & 0.5 & $0.05-5.45$ & 0.57 \\
\hline & & & $96 \mathrm{~m}$ & 1.7 & $0.94-3.07$ & 0.08 \\
\hline Manickam, 2012 [24] & & MDT vs. ROM & $6 \mathrm{~m}$ & 1.43 & $0.56-3.64$ & 0.46 \\
\hline \multirow[t]{3}{*}{ Fajardo 2009 [30] } & $\mathrm{MB}$ & MDT $2 y$ vs. MDT $1 y+1$ month daily RFP/ofloxacin & $144 \mathrm{~m}$ & 0.51 & $0.05-5.46$ & 0.58 \\
\hline & & MDT 2y vs. 1 month daily RFP/ofloxacin & & 0.11 & $0.02-0.87$ & 0.04 \\
\hline & & MDT $2 y$ vs. MDT 1 y & & 0.05 & $0.01-0.37$ & $<0.05$ \\
\hline Olivera Penna, 2017 [35] & & MDT vs. RFP + dapsone + clofazimine $\times 6 \mathrm{~m}$ & $60 \mathrm{~m}$ & 0.16 & $0.02-1.29$ & 0.08 \\
\hline \multirow[t]{3}{*}{ Souza Cunha, 2012 [38] } & & MDT 1y vs. MDT x 2y & $84 \mathrm{~m}$ & 2.59 & $0.13-52.17$ & 0.53 \\
\hline & & MDT 1y vs. MDT + ofloxacin & & 1.04 & $0.15-7.10$ & 0.97 \\
\hline & & MDT 1y vs. ofloxacin + RFP & & 0.13 & $0.03-0.51$ & $<0.05$ \\
\hline Villahermosa, 2004 [40] & & MDT vs. ROM & $96 \mathrm{~m}$ & \multicolumn{3}{|c|}{ No events reported } \\
\hline \multicolumn{7}{|l|}{$\mathrm{Bl}$} \\
\hline Study & Patients & Comparison & Follow up & $\mathrm{MD}$ & $95 \% \mathrm{Cl}$ & $p$ value \\
\hline Bathki, 1992 [29] & $\mathrm{MB}$ & MDT vs. MDT + vaccine & $24 \mathrm{~m}$ & 1.3 & $0.48,2.12$ & $<0.05$ \\
\hline Gunawan 2018 [32] & & MDT vs. CDC & $3 \mathrm{~m}$ & 0.03 & $-0.03,0.09$ & 0.75 \\
\hline Jadav, 1992 [33] & & MDT vs. RFP + dapsone + clofazimine & $24 \mathrm{~m}$ & 0.41 & $0.12,0.70$ & $<0.05$ \\
\hline Olivera Penna, 2017 [35] & & MDT vs. RFP+ dapsone + clofazimine $\times 6 \mathrm{~m}$ & $60 \mathrm{~m}$ & -0.15 & $-1.06,0.76$ & 0.34 \\
\hline \multirow[t]{2}{*}{ Sampoonachut, $1997^{\complement}[36]$} & & MDT vs. MDT + ofloxacin. & $36 \mathrm{~m}$ & -0.07 & $-0.48,0.34$ & 0.74 \\
\hline & & MDT vs. Ofloxacin + clofazimine, then MDT & & -0.68 & $-1.10,-0.26$ & $<0.05$ \\
\hline Shaw, $2003^{\mathrm{c}}[37]$ & & MDT vs. RFP + clofazimine + acedapsone + dapsone & $24 \mathrm{~m}$ & 0.1 & $-0.34,0.54$ & 0.66 \\
\hline
\end{tabular}

Abbreviations. - BI Bacillary index, CDC Clarithromycin+ dapsone+ clofazimine, $m$ Months, MDT Multidrug treatment, ROM Rifampin, ofloxacin and minocycline

${ }^{a}$ Included a period of direct observation

${ }^{\mathrm{b}}$ Maximum Improvement score at the end of treatment; no other information reported

'SD not reported 
world, being India the most common country (11 studies).

Comparison treatments varied between studies. The most common treatment was a single monthly dose of rifampin, ofloxacin and minocycline (ROM) used in 8 studies (6 of PB and 2 of MB leprosy). The outcomes evaluated were also markedly heterogeneous, as it can be seen in Tables 1 and 2.

\section{Quality assessment}

The overall risk of bias of the included trials was considered moderate to high. The vast majority of the studies did not clearly report the items evaluated. Most of the included trials reported they attrition rate during the follow up (18 out of 20), with a mean of $10.5 \%$ (Fig. 2). One observational study was included. Quality was evaluated using the Newcastle- Ottawa scale. Details are presented in Additional file 2.

\section{Outcomes of interest Efficacy outcomes}

Complete clinical cure Complete clinical cure was evaluated in 9 studies that included patients with PB leprosy. It was not evaluated in MB leprosy.

A meta-analysis of 5 studies comparing MDT vs. ROM did not show statistically significant difference between them after 6 months of treatment (RR 1.06, 95\% CI $0.88-1.27, p=0.56$ ). When the same comparison was evaluated at the end of the study period (range 6-36 months) in 6 studies, ROM was not better than MDT (RR 1.01, 95\% CI 0.78-1.31, $p=0.93$ ). The studies with more participants that were included in the analysis had significant and contrary results with RR of 1.14 (95\%CI 1.02-1.27) by Babu et al., 1997 and 0.73 (95\% CI 0.690.77 ) by Manickam et al., 2012 (Fig. 3a and b).

The addition of clofazimine to PB MDT did not show significant improvement. This and other available comparisons are shown in Table 3.
Clinical improvement This outcome was assessed in 5 studies evaluating $\mathrm{PB}$ leprosy and in 3 evaluating $\mathrm{MB}$ leprosy. All of them used clinical scores that considered the characteristics of the lesions. Evaluated criteria included erythema, hypopigmentation, infiltration, anesthesia, nerve involvement and size. Since the scoring systems were not consistent between studies, we decided to analyze this outcome using standardized mean difference (SMD).

A meta-analysis of 4 studies comparing MDT vs. ROM in patients with PB leprosy showed a difference between both treatments (Standard mean difference 1.33 (95\% CI -1.43- -1.23)). However, this difference was led by one study with significant results and high number of participants (Manickam 2012), additionally the $\mathrm{I}^{2}$ show great heterogeneity (Fig. 4). Also, the addition of clofazimine to MDT did not show any significant improvement in this population (SMD 0.28, 95\% CI -0.16$0.72, p=0.22$ ).

Two of the studies (Sampoonachut 1997 and Tejasvi 2006) evaluating patients with MB leprosy reported clinical improvement as a dichotomous outcome; none of them reported enough information for the development of a pooled estimated. Villahermosa 2004 reported an improvement score (Table 3).

Treatment failure Three studies evaluating PB leprosy patients included treatment failure as their outcomes. These studies evaluated MDT vs. ROM in PB leprosy and no statistically significant difference between the treatment arms was found (Fig. 5).

Relapse This outcome was evaluated in 8 studies. Two studies used ROM as their comparison for patients with $\mathrm{PB}$ leprosy and one for MB leprosy. The pooled estimate of the studies in patients with PB leprosy showed no difference between both regimes (RR 1.62, 95\% CI 0.982.67, $p=0.06$ ) but there seem to be a tendency to favor ROM (Fig. 6). The big difference in follow up periods complicates the interpretation of this estimate $(6$ months

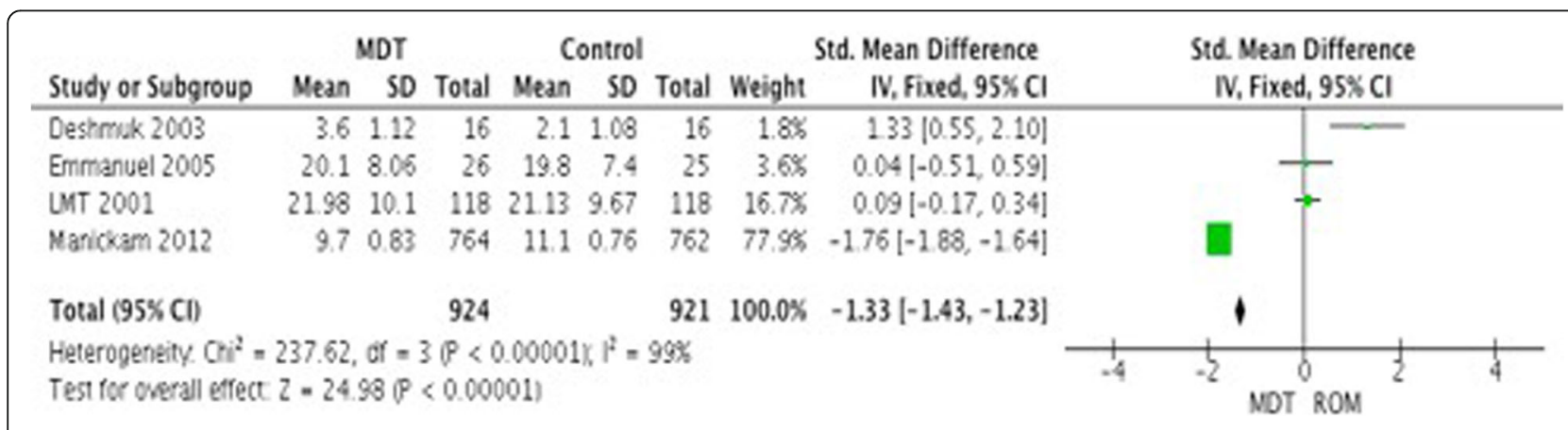

Fig. 4 Clinical improvement in patients with PB leprosy: MDT vs. ROM at the end of follow up period 


\begin{tabular}{|c|c|c|c|c|c|c|c|}
\hline Study or Subgroup & \multicolumn{2}{|c|}{ MDT } & \multicolumn{2}{|c|}{ ROM } & Weight & $\begin{array}{c}\text { Risk Ratio } \\
\text { IV, Random, } 95 \% \mathrm{Cl}\end{array}$ & $\begin{array}{c}\text { Risk Ratio } \\
\text { IV, Random, } 95 \% \mathrm{CI}\end{array}$ \\
\hline Babu 1997 & 6 & 744 & 6 & 744 & $35.5 \%$ & $1.00[0.32,3.09]$ & \\
\hline Deshmuk 2003 & 6 & 16 & 4 & 16 & $40.2 \%$ & $1.50[0.52,4.32]$ & \\
\hline LMT 2001 & 4 & 118 & 4 & 118 & $24.3 \%$ & $1.00[0.26,3.90]$ & \\
\hline Total $(95 \% \mathrm{CI})$ & & 878 & & 878 & $100.0 \%$ & $1.18[0.60,2.30]$ & \\
\hline Total events & 16 & & 14 & & & & \\
\hline $\begin{array}{l}\text { Heterogeneity. Taü }{ }^{2}= \\
\text { Test for overall effect: }\end{array}$ & $\begin{array}{l}0.00 ; \mathrm{Ch} \\
2=0.48\end{array}$ & $\begin{array}{l}i^{2}=0 \\
(P=0\end{array}$ & $\begin{array}{l}34, \mathrm{df}= \\
63)\end{array}$ & $2(P=$ & $0.84) ; 1^{2}$ & $=0 \%$ & MDT ROM \\
\hline
\end{tabular}

Fig. 5 Treatment failure in patients with PB leprosy: MDT vs. ROM at the end of follow up period

vs. 8 years). Additionally, the study evaluating MB leprosy did not report any relapses.

None of the regimes evaluated showed any benefit over MDT for patients with $\mathrm{PB}$ leprosy or MB leprosy (Table 3).

Bacillary index (BI) improvement BI was exclusively reported for MB leprosy. Six studies evaluated this outcome. In this case, most of the alternate regimes achieved better reductions of BI compared to MDT. Detailed results are reported in Table 3 .

\section{Safety outcomes}

Side effects We intended to evaluate mild-moderate and severe side effects independently; unfortunately, most studies did not report their outcomes in this way. The development of side effects was analyzed as a single outcome.

Three studies reported side effects in patients with PB leprosy. No statistically significant difference was seen in patients receiving MDT or ROM (Fig. 7).

This outcome was reported in 4 studies evaluating patient with MB leprosy. Each study evaluated a different comparison. Individual estimates are reported in Table 4.

\section{Immunological reactions}

Type I reaction This outcome was evaluated in 11 studies (6 PB and $5 \mathrm{MB})$. A meta-analysis comparing MDT vs. ROM in patients with PB leprosy did not show a statistically significant difference between the interventions (RR 0.99, 95\%CI 0.31-3.18, $p=0.99$, Fig. 8). Other studies evaluating this outcome are reported in Table 4.

Type II reaction This outcome was evaluated in 9 studies $(1 \mathrm{~PB}$ and $8 \mathrm{MB})$. We were not able to develop a meta-analysis. In patients with MB leprosy the combination of dapsone, rifampin and clofazimine showed a statistically significant reduction in the development of type II reaction. On the other hand, the use of MDT regimen for 2 years increased the development of this outcome in the same population when compared to the use of MDT for 1 year. No other statistically significant differences were observed (Table 4).

Neuritis The development of neuritis was evaluated in 7 studies (3 PB and $4 \mathrm{MB}$ ). When MDT was compared to rifampin, dapsone and clofazimine for 6 months in patients with MB leprosy a statistically significant difference between groups was seen (Table 4).

\section{Discussion}

Main findings

This study aimed to summarize all the evidence available on WHO MDT treatment effectiveness, safety and immunological reactions for leprosy. One of the aspects that surprised us the most was to see the poor scientific production for a thousand-year-old disease, the lack of standardization in definition of diagnostic criteria, outcome objectives and time for follow up and if we add to

\begin{tabular}{|c|c|c|c|c|c|c|c|c|c|c|}
\hline \multirow{2}{*}{ Study or Subgroup } & \multicolumn{2}{|c|}{ MDT } & \multicolumn{2}{|c|}{ ROM } & \multirow{2}{*}{ Weight } & \multirow{2}{*}{$\begin{array}{l}\text { Risk Ratio } \\
\mathrm{M}-\mathrm{H} \text {, Random, } 95 \% \mathrm{Cl}\end{array}$} & \multicolumn{3}{|c|}{$\begin{array}{ll} & \text { Risk Ratio } \\
\mathrm{M}-\mathrm{H}, \text { Random, } 95 \% \mathrm{Cl}\end{array}$} & \\
\hline & Events & Iotal & Events & Iotal & & & & & & \\
\hline $\begin{array}{l}\text { Kuemar } 2015 \\
\text { Manickam } 2012\end{array}$ & $\begin{array}{l}10 \\
29\end{array}$ & $\begin{array}{l}134 \\
764\end{array}$ & $\begin{array}{r}7 \\
17\end{array}$ & $\begin{array}{l}134 \\
762\end{array}$ & $\begin{array}{l}28.5 \% \\
71.5 \%\end{array}$ & $\begin{array}{l}1.43[0.56,3.64] \\
1.70[0.94,3.07)\end{array}$ & & & - & \\
\hline Total $(95 \% \mathrm{Cl})$ & & 898 & & 896 & $100.0 \%$ & $1.62[0.98,2.67]$ & & & & \\
\hline Total events & 39 & & 24 & & & & & & & \\
\hline $\begin{array}{l}\text { Heterogeneity. Tau² } \\
\text { Test for overal effer }\end{array}$ & $\begin{array}{l}0.00 ; \mathrm{Cr} \\
2=1.89\end{array}$ & $\begin{array}{l}h^{2}=0 \\
9 P=0\end{array}$ & $\begin{array}{l}10, d f= \\
0.061\end{array}$ & $1 \beta=$ & $0.76)_{1}^{2}=$ & $=0 \%$ & 0.10 .2 & ${ }_{\text {MDT }}^{0.5}$ & $1_{\text {ROM }}^{2}$ & 510 \\
\hline
\end{tabular}




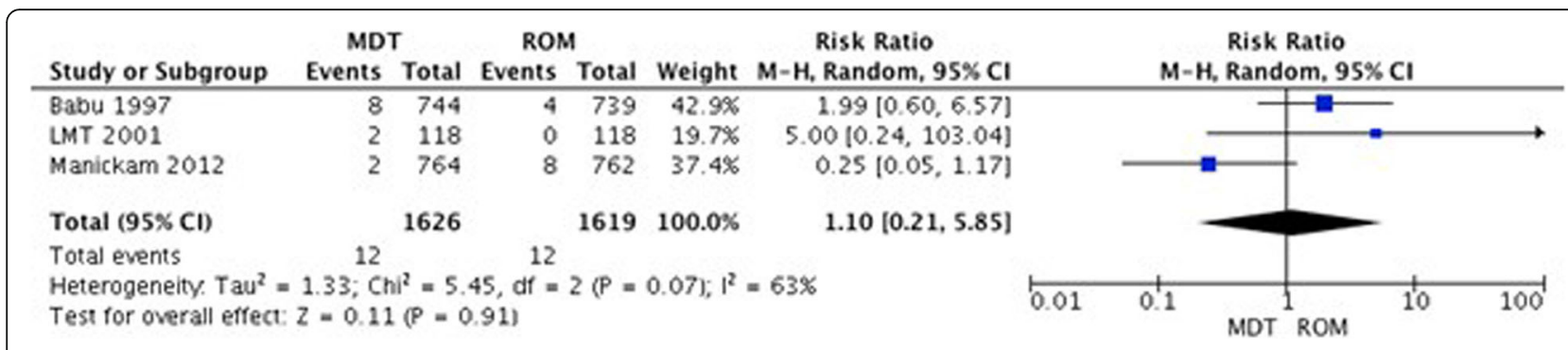

Fig. 7 Adverse events in patients with PB leprosy: MDT vs. ROM at the end of the follow up period

this the poor methodological quality of the majority of studies found, show us a situation that support the denomination and let us understand what leprosy is a neglected disease.

It was precisely this potentially high risk of bias studies that did not let bring a consensus: MDT seems to have a better treatment outcome (clinical improvement) compared with ROM at the end of the follow up period, however we did not find differences in complete cure at 6 months of treatment or at the end of follow up period. When MDT is compared with other treatment, we did not find differences in treatment outcomes.

MDT, as is noted above, had almost no difference in a better response for cured and reduced relapse rate, compared with ROM and other treatments schemes, since most of the magnitudes of these differences are small. However, these schemes had a great success rate after 1 or 2 years of follow-up. These results can confirm the useful role of MDT in leprosy treatment, however also reveals gaps in the evidence to improve it: there is lack of information about adherence in these long-time treatments (MDT, ROM and others), together with the lack of resistance pattern of relapse cases, this successful treatment scheme can be in jeopardized by the increasing rate of relapse cases and the unknown effect of resistance epidemiology of $M$. leprae $[8,41,42]$. Recently the new guidelines of WHO states that "The same 3drug regimen of rifampicin, dapsone and clofazimine may be used for all leprosy patients, with a duration of treatment of 6 months for PB leprosy and of 12 months for $\mathrm{MB}$ leprosy. (Strength: conditional, quality of evidence: low)". However, they mentioned that "evidence on the potential benefits and harms of a shorter (6month) 3-drug regimen was limited and inconclusive, with a potential increase in the risk of relapse. Therefore, the Guideline Development Group determined that there was not enough evidence of equivalent outcomes to support a recommendation to shorten the treatment duration for MB leprosy" [43]". The decision was taken based in only one study [27] which, although it shows an interesting design, its non-randomized and has a very low quality of evidence [44]. Also, the study has not been valued in comparison with other studies, and besides these, its findings had not been supported by a RCT [35].

Is in this context, where supported treatment are required (leprosy programs were reduced their support in the last years) [8], new treatment schemes are needed, considering WHO MDT had more than 30 years of use. However, new treatment should be based in evidence and not only in logistical aspects.

\section{Limitations and strengths}

This study has limitations: primary studies showed high risk of bias, specifically regarding allocation and blinding. Also, most of the studies did not report treatment adherence (a factor for poor treatment outcomes) or comorbidities such as HIV/AIDS that can affect treatment outcomes. Other confounders such as age, gender, and previous treatment should be also considered in the analysis. These limitations can affect (in any direction and in magnitude) the measures of associations reported in primary studies. Another limitation of primary studies was the heterogeneous report of treatment outcomes, so a proper comparison between treatments was very difficult, e.g. almost a third part of treatment outcome evaluation was with different clinical scores, which applied diverse items and can be affected by evaluator bias. Future studies evaluating clinical effectiveness of leprosy treatment should be use standard treatment outcomes, with laboratory definitions and/or biomarkers of success, with the aim to compare different settings and clinical characteristics.

Finally, none of these studies reported antibiotic resistance pattern of $M$. leprae. There are reports on drug resistance in leprosy patients [45-49] and can be one of the reasons of the relapse rate increase in the last years [50]. Considering some of the areas with leprosy had also high incidence of resistant tuberculosis (such us India) and MDT share rifampin as an important drug with sensitive tuberculosis, closer follow-up and drug resistance studies should be done in these areas.

However, it is important to mention that studies with people with leprosy are conducted in low resources settings where sophisticated methods of follow-up are not possible, due to lack of money and interest of higher authorities. 
Table 4 Safety Outcomes and Immunological Reactions

\begin{tabular}{|c|c|c|c|c|c|c|}
\hline \multicolumn{7}{|l|}{ Side Effects } \\
\hline Study & Patients & Comparison & Follow up & $\mathrm{RR}$ & $95 \% \mathrm{Cl}$ & $p$ value \\
\hline Balagon, 2010 [18] & PB & MDT vs. 28 days of RFP + ofloxacin for $4 \mathrm{w}$ then $5 \mathrm{~m}$ of placebo & $12 \mathrm{~m}$ & 0.38 & $0.10-1.39$ & 0.14 \\
\hline Gunawan 2018 [32] & $\mathrm{MB}$ & MDT vs. CDC & $3 \mathrm{~m}$ & \multicolumn{3}{|c|}{ Unable to analyze } \\
\hline Tejasvi, 2006 [39] & & MDT vs. RFP + sparfloxacin + clarithromycin + minocycline & $12 \mathrm{~m}$ & 0.1 & $0.01-1.56$ & 0.1 \\
\hline Shaw, 2003 [37] & & MDT vs. RFP + clofazimine+ acedapsone + dapsone & $24 \mathrm{~m}$ & 1.42 & $0.58-3.47$ & 0.44 \\
\hline \multicolumn{7}{|l|}{ Type I reaction } \\
\hline Study & Patients & Comparison & Follow up & $\mathrm{RR}$ & $95 \% \mathrm{Cl}$ & $p$ value \\
\hline Orege, $1990[26]$ & $\mathrm{PB}$ & MDT vs. MDT + RFP + dapsone ${ }^{a}$ & $6 \mathrm{~m}$ & 1.15 & $0.58-2.27$ & 0.69 \\
\hline Fernandes Pena 2012 [31] & MB & MDT vs. Monthly RFP, dapsone and clofazimine daily $\times 6 \mathrm{~m}$ & $60 \mathrm{~m}$ & 1.1 & $0.86-1.41$ & 0.44 \\
\hline \multirow[t]{2}{*}{ Sampoonachut, 1997 [36] } & & MDT vs. MDT + ofloxacin & $12 \mathrm{~m}$ & 2.11 & $0.21-21.36$ & 0.53 \\
\hline & & MDT vs. Ofloxacin + clofazimine, then MDT & & 1 & $0.16-6.38$ & 1 \\
\hline Shaw, 2003 [37] & & MDT vs. RFP + Clofazimine+ Acedapsone + dapsone & $24 \mathrm{~m}$ & 1.78 & $0.53-5.97$ & 0.35 \\
\hline Tejasvi, 2006 [39] & & MDT vs. RFP + sparfloxacin + clarithromycin + minocycline & $12 \mathrm{~m}$ & 0.21 & $0.01-3.71$ & 0.29 \\
\hline Villahermosa, 2004 [40] & & MDT vs. ROM & $96 \mathrm{~m}$ & 0.91 & $0.37-2.23$ & 0.83 \\
\hline \multicolumn{7}{|l|}{ Type II reaction } \\
\hline Study & Patients & Comparison & Follow up & $\mathrm{RR}$ & $95 \% \mathrm{Cl}$ & $p$ value \\
\hline Babu, 1997 [17] & PB & MDT vs. ROM & $18 \mathrm{~m}$ & \multicolumn{3}{|c|}{ No events reported } \\
\hline Balagon, 2011 [28] & MB & MDT 1y vs. MDT 2y & $24 \mathrm{~m}$ & 1.53 & $1.05-2.23$ & 0.03 \\
\hline Fernandes Pena 2012 [31] & & MDT vs. Monthly RFP, dapsone and clofazimine daily $\times 6 \mathrm{~m}$ & $60 \mathrm{~m}$ & 1.15 & $0.72-1.84$ & 0.56 \\
\hline Jadhav, 1992 [33] & & MDT vs. RFP + dapsone + clofazimine & $24 \mathrm{~m}$ & 0.22 & $0.07-0.72$ & 0.01 \\
\hline Maghanoy, 2018 [34] & & MDT vs. MDT + 12 months of clofazimine & $24 \mathrm{~m}$ & 0.86 & $0.52-1.40$ & 0.54 \\
\hline \multirow[t]{2}{*}{ Sampoonachut, 1997 [36] } & & MDT vs. MDT + ofloxacin. & $24 \mathrm{~m}$ & 0.7 & $0.13-3.75$ & 0.68 \\
\hline & & MDT vs. ofloxacin + clofazimine, then MDT & & 1 & $0.16-6.38$ & 1 \\
\hline Shaw, 2003 [37] & & MDT vs. RFP + clofazimine+ acedapsone + dapsone & $24 \mathrm{~m}$ & 0.44 & $0.04-4.45$ & 0.49 \\
\hline Tejasvi, 2006 [39] & & MDT vs. RFP + sparfloxacin + clarithromycin + minocycline & $12 \mathrm{~m}$ & \multicolumn{3}{|c|}{ No events reported } \\
\hline Villahermosa, 2004 [40] & & MDT vs. ROM & $96 \mathrm{~m}$ & 0.91 & $0.16-5.30$ & 0.92 \\
\hline \multicolumn{7}{|l|}{ Neuritis } \\
\hline Study & Patients & Comparison & Follow up & $\mathrm{RR}$ & $95 \% \mathrm{Cl}$ & $p$ value \\
\hline Manickam, 2012 [24] & PB & MDT vs. ROM & $6 \mathrm{~m}$ & 0.5 & {$[0.05,5.49]$} & 0.57 \\
\hline Bathe, 1986 [19] & & MDT vs. MDT+ clofazimine & $24 \mathrm{~m}$ & 4 & {$[0.47,34.24]$} & 0.21 \\
\hline Katoch, 1999 [22] & & MDT vs. MDT+ clofazimine & $24 \mathrm{~m}$ & \multicolumn{3}{|c|}{ No events reported } \\
\hline Fernandes Pena 2012 [31] & MB & MDT vs. RFP, dapsone and clofazimine $\times 6 \mathrm{~m}$ & $60 \mathrm{~m}$ & 0.64 & $0.45,0.92$ & 0.01 \\
\hline Jadhav, 1992 [33] & & MDT vs. RFP + dapsone + clofazimine & $24 \mathrm{~m}$ & 0.29 & $0.03-2.69$ & 0.28 \\
\hline \multirow[t]{2}{*}{ Sampoonachut, 1997 [36] } & & MDT vs. MDT + ofloxacin & $24 \mathrm{~m}$ & 2.11 & $0.21,21.36$ & 0.53 \\
\hline & & MDT vs. ofloxacin + clofazimine, then MDT & & 1 & $0.16-6.38$ & 1 \\
\hline Shaw, 2003 [37] & & MDT vs. RFP + clofazimine+ acedapsone + dapsone & $24 \mathrm{~m}$ & 1.19 & $0.31-4.51$ & 0.8 \\
\hline
\end{tabular}

Abbreviations - BI Bacillary index, CDC Clarithromycin+dapsone+clofazimine, RFP Rifampin; m: months, MDT Multidrug treatment, ROM, rifampin, ofloxacin and minocycline

ancluded a period of direct observation,

\section{Implications for practice and research}

As a stigmatizing disease for centuries, leprosy is nowadays affecting vulnerable populations in the tropics (especially in rural and semi-rural areas), where health systems are weak and other diseases (such as dengue, malaria, HIV/AIDS or tuberculosis) have more preponderance in public health funding [51, 52]. Health determinants affects in several areas (such as poverty, education, water and sanitation, gender and others), reason why treatment alone is not the most effective way to eliminate the disease [53]. In addition, leprosy control faces many barriers regarding clinical management, 


\begin{tabular}{|c|c|c|c|c|c|c|c|c|c|c|}
\hline Study or Subgroup & $\begin{array}{l}\text { MDT } \\
\text { Events }\end{array}$ & Total & \multicolumn{2}{|c|}{ ROM } & Weight & $\begin{array}{c}\text { Risk Ratio } \\
\mathrm{M}-\mathrm{H}, \text { Random, } 95 \% \mathrm{Cl} \\
\end{array}$ & \multicolumn{3}{|c|}{$\begin{array}{c}\text { Risk Ratio } \\
\mathrm{M}-\mathrm{H}, \text { Random, } 95 \% \mathrm{CI}\end{array}$} & \\
\hline Babu 1997 & 2 & 744 & 1 & 739 & $23.5 \%$ & $1.99[0.18,21.86]$ & & & $\Longrightarrow$ & \\
\hline Deshmuk 2003 & 3 & 16 & 1 & 16 & $29.1 \%$ & $3.00[0.35,25.87]$ & & & $\Longrightarrow$ & \\
\hline Emmanuel 2005 & 0 & 26 & 2 & 25 & $15.1 \%$ & $0.19[0.01,3.82]$ & $\longleftarrow$ & & & \\
\hline LMT 2001 & 0 & 118 & 2 & 118 & $14.7 \%$ & $0.20[0.01,4.12]$ & $\longleftarrow$ & & & \\
\hline Manickam 2012 & 1 & 764 & 1 & 762 & $17.6 \%$ & $1.00[0.06,15.92]$ & & & & \\
\hline Total $(95 \% \mathrm{Cl})$ & & 1668 & & 1660 & $100.0 \%$ & $0.99[0.31,3.18]$ & & & & \\
\hline Total events & 6 & & 7 & & & & & & & \\
\hline $\begin{array}{l}\text { Heterogeneity: } \text { Tau }^{2}= \\
\text { Test for overall effect: }\end{array}$ & $\begin{array}{l}0.00 ; C h \\
z=0.01\end{array}$ & $\begin{array}{l}i^{2}=3.6 \\
(P=0\end{array}$ & $\begin{array}{l}\text { 62, } d f= \\
.991\end{array}$ & $4(P=$ & $0.46) ; 1^{2}$ & $=O \%$ & 0.01 & 0.1 & ROM & 100 \\
\hline
\end{tabular}

starting with the lack of funding for research, its characteristic as a silent disease, and unavailable measures for prevention (i.e. an effective vaccine). A delayed diagnosis and treatment usually lead to disability, which regardless the success of treatment, will lead to the necessity of access to health care and rehabilitation for long time, sometimes lifelong [54]. In addition, there are not new drugs in the pipeline to reduce treatment duration, and the only drug in research phase is bedaquiline (which is also one of the new drugs for tuberculosis after more than 30 years of tuberculosis treatment), which showed a bactericidal effect against $M$. leprae in animal models $[55,56]$. Now, Bedaquiline is being tested in a Phase 2 trial (not started yet) for MB leprosy in Brazil [57], however, as in the case of tuberculosis, we need new drugs that can be combined to reduce the burden of $M$. leprae, specially in an context of increasing antibiotic resistance, providing a safe and short leprosy treatment.

\section{Conclusions}

None of the evaluated regimes showed any benefit over MDT for patients with $\mathrm{PB}$ or $\mathrm{MB}$ for relapses. The addition of clofazimine to PB MDT did not show significant improvement.

It is necessary to standardize criteria for diagnosis, cure, and follow-up in the search for more and better evidence to fill existing gaps in information that evaluates the new available antibiotics.

Further studies evaluating adherence to the treatment, potential development of drug resistance and short treatment regimens based in evidence are needed to reach the goal of leprosy elimination.

\section{Supplementary information}

Supplementary information accompanies this paper at https://doi.org/10. 1186/s12879-019-4665-0.

Additional file 1. Search strategy. Search strategies for the different databases.
Additional file 2. Quality assesment using the Newcastle- Ottawa scale. Quality assessment for non-RCT studies using the Newcastle-Ottawa scale.

\section{Abbreviations}

BI: Bacillary Index; Cl: Confidence Intervals; ENL: Erythema Nodosum Leprosorum; HIV/AIDS: Human Immunodeficiency Virus/Acquired Immune Deficiency Syndrome; MB: Multibacillary; MD: Mean difference; MDT: Multidrug Therapy; NHDP: National Hansen's Diseases Programs; PB: Paucibacillary; RCT: Randomized Controlled Trials; ROM: RifampinOfloxacin-Minocycline; RR: Relative Risk; SDM: Standardized Mean Difference; TB: Tuberculosis; WHO: World Health Organization

\section{Acknowledgements}

We would like to thank to the School of Medicine "Alberto Hurtado", Universidad Peruana Cayetano Heredia for its support to the publication of the study.

\section{Authors' contributions}

Study design: GJP, JPD, PB, GM. Search Strategy: LJP. Abstract Review: PB, $A A V, C C L$, JPD, GJP. Full text: PB, CCL, AAV, MLP. Data Extraction: AAV, MLP. Data Analysis: GJP, MLP. Quality Assessment: JCTT, OP. Manuscript Writing: JCTT, OP, CUG, GJP, MLP, GM. Approval of the final draft: All the authors

Funding

Maria Lazo-Porras is funded by the Swiss Goverment Excellence Scholarship (2018.0698). No funding for conducted the present study.

\section{Availability of data and materials}

Maria Lazo-Porras and Gabriela J. Prutsky had full access to all the data in the study and take responsibility for the integrity of the data and the accuracy of the data analysis. Data will be provided under request to the first authors.

Ethics approval and consent to participate

Not applicable.

\section{Consent for publication}

All the authors give their authorization to publish the article.

\section{Competing interests}

The authors declare that they have no competing interests.

\section{Author details}

'CONEVID Unidad de Conocimiento y Evidencia, School of Medicine "Alberto Hurtado", Universidad Peruana Cayetano Heredia, Av. Honorio Delgado 430, Lima 31, Peru. ${ }^{2}$ Division of Tropical and Humanitarian Medicine, Geneva University Hospitals and University of Geneva, Geneva, Switzerland.

${ }^{3}$ Department of Pediatrics, Mayo Clinic Health System, Mankato, MN, USA. ${ }^{4}$ Instituto de Medicina Tropical Alexander von Humboldt, Universidad Peruana Cayetano Heredia, Lima, Peru. ${ }^{5}$ Montefiore Medical Center-Albert Einstein College of Medicine, Bronx, New York, USA. 'Division of Pulmonary and Critical Care Medicine, Mayo Clinic, Rochester, MN, USA. ${ }^{7}$ Cardiology division, Jackson Memorial Hospital, Miami, Florida, USA. ${ }^{8}$ Evidence-based 
Practice Center, Mayo Clinic, Rochester, MN, USA. ${ }^{9}$ School of Medicine "Alberto Hurtado", Universidad Peruana Cayetano Heredia, Lima, Peru. ${ }^{10}$ Hospital de la Santa Creu i Sant Pau, Institut d'Investigació Biomèdica Sant Pau, and Universitat Autònoma de Barcelona, Barcelona, Spain. ${ }^{11}$ Faculty of Infectious and Tropical Diseases, London School of Hygiene and Tropical Medicine, London, UK.

\section{Received: 14 June 2019 Revised: 1 November 2019}

\section{Accepted: 28 November 2019 Published online: 20 January 2020}

\section{References}

1. WHO. Global leprosy situation, 2010. Weekly epidemiological record. 2010;85: 337-348. Available from: https:/www.who.int/wer/2010/wer8535.pdf?ua=1.

2. Scollard DM, Adams LB, Gillis TP, Krahenbuhl JL, Truman RW, Williams DL. The continuing challenges of leprosy. Clin Microbiol Rev. 2006;19(2):338-81.

3. WHO. Global leprosy situation, 2012. Weekly epidemiological record. 2012;87: 317-328. Available from: https://www.who.int/wer/2012/wer8734.pdf?ua=1

4. WHO. Global leprosy update, 2014: need for early case detection. Weekly epidemiological record. 2015;90:461-76. Available from: https://www.who. int/wer/2015/wer9036.pdf?ua=1.

5. Levy L, Ng H, Evans MJ, Krahenbuhl JL. Susceptibility of thymectomized and irradiated mice to challenge with several organisms and the effect of dapsone on infection with Mycobacterium leprae. Infect Immun. 1975;11(5): 1122-32.

6. Ji B. Why multidrug therapy for multibacillary leprosy can be shortened to 12 months. Lepr Rev. 1998:69(2):106-9.

7. Dacso MM, Jacobson RR, Scollard DM, Stryjewska BM, Prestigiacomo JF. Evaluation of multi-drug therapy for leprosy in the United States using daily rifampin. South Med J. 2011;104(10):689-94.

8. Lockwood DN, Kumar B. Treatment of leprosy. BMJ. 2004;328(7454):1447-8.

9. Moher D, Liberati A, Tetzlaff J, Altman DG, Group P. Preferred reporting items for systematic reviews and meta-analyses: the PRISMA statement. Int J Surg. 2010;8(5):336-41.

10. Kaimal S, Thappa DM. Relapse in leprosy. Indian J Dermatol Venereol Leprol. 2009;75(2):126-35.

11. Higgins JPT, Green S. Cochrane Handbook for Systematic Reviews of Interventions Version 5.1.0 2011, [updated March 2011] [cited 2016 December]. Available from: http://handbook.cochrane.org/.

12. Wells GA, Shea B, O'Connell D, Peterson J, Welch V, Losos M, et al. The Newcastle-Ottawa scale (NOS) for assessing the quality of nonrandomised studies in meta-analyses 2000 [cited 2016]. Available from: http://www.ohri. ca/programs/clinical_epidemiology/oxford.asp.

13. DerSimonian R, Laird N. Meta-analysis in clinical trials. Control Clin Trials. 1986;7(3):177-88.

14. Higgins JP, Thompson SG. Quantifying heterogeneity in a meta-analysis. Stat Med. 2002:21(11):1539-58.

15. Lau J, loannidis JP, Terrin N, Schmid CH, Olkin I. The case of the misleading funnel plot. BMJ. 2006:333(7568):597-600.

16. Lesion Multicentre Trial G. A comparative trial of single dose chemotherapy in paucibacillary leprosy patients with two to three skin lesions. Indian J Lepr. 2001;73(2):131-43.

17. Single-lesion Multicentre Trial group. Efficacy of single dose multidrug therapy for the treatment of single-lesion paucibacillary leprosy. Indian J Lepr. 1997;69(2):121-9.

18. Balagon MF, Cellona RV, Abalos RM, Gelber RH, Saunderson PR. The efficacy of a four-week, ofloxacin-containing regimen compared with standard WHO-MDT in PB leprosy. Lepr Rev. 2010;81(1):27-33.

19. Bhate RD, Gupta CM, Chattopadhyay SP, Singh IP. Experience with multidrug therapy in paucibacillary leprosy. Indian J Lepr. 1986;58(2):244-50.

20. Deshmukh AR, Dhurat RS, Jerajani HR. A comparative clinico-pathological study of single dose ROM in paucibacillary leprosy patients with 1-3 skin lesions. Indian J Lepr. 2003;75(3):209-17.

21. Emmanuel M, Gupte MD. Lesional characteristics and histopathology in paucibacillary leprosy patients with 2 or 3 skin lesions: comparison between ROM and PB-MDT regimens. Indian J Lepr. 2005;77(1):19-25.

22. Katoch K, Natarajan M, Katoch VM, Singh HB, Bhatia AS. Chemotherapy trial in paucibacillary leprosy using clofazimine. Indian J Lepr. 1999;71(3):311-24.

23. Kumar A, Girdhar A, Girdhar BK. A randomized controlled trial to compare cure and relapse rate of paucibacillary multidrug therapy with monthly rifampicin, ofloxacin, and minocycline among paucibacillary leprosy patients in Agra District, India. Indian J Dermatol, Venereol leprol. 2015;81(4):356-62.
24. Manickam P, Nagaraju B, Selvaraj V, Balasubramanyam S, Mahalingam VN, Mehendale SM, et al. Efficacy of single-dose chemotherapy (rifampicin, ofloxacin and minocycline-ROM) in PB leprosy patients with 2 to 5 skin lesions, India: randomised double-blind trial. Indian J Lepr. 2012:84(3):195-207.

25. Mathai R, George S, Jacob M. Fixed duration MDT in paucibacillary leprosy. International journal of leprosy and other mycobacterial diseases : official organ of the International Leprosy Association. 1991;59(2):237-41.

26. Orege PA, Obura M, Okelo C, Okuku P, Makokha S, Nyawalo J. Multidrug therapy for treatment of paucibacillary leprosy in western Kenya-preliminary communications. East Afr Med J. 1990;67(9):632-9.

27. Rao PN, Suneetha S, Pratap DVS. Comparative study of uniform-MDT and WHO-MDT in Pauci and multi bacillary leprosy patientsover 24 months of observation. Lepr Rev. 2009;80:143-55.

28. Balagon M, Saunderson PR, Gelber RH. Does clofazimine prevent erythema nodosum leprosum (ENL) in leprosy? A retrospective study, comparing the experience of multibacillary patients receiving either 12 or 24 months WHO-MDT. Lepr Rev. 2011;82(3):213-21

29. Bhatki WS, Chulawala RG. Immunotherapeutic potential of ICRC vaccine: a case control study. Lepr Rev. 1992:63(4):358-64.

30. Fajardo TT, Villahermosa L, Pardillo FE, Abalos RM, Burgos J, Dela Cruz E, et al. A comparative clinical trial in multibacillary leprosy with long-term relapse rates of four different multidrug regimens. The American journal of tropical medicine and hygiene. 2009;81(2):330-4.

31. Penna ML, Buhrer-Sekula S, Pontes MA, Cruz R, Goncalves Hde S, Penna GO. Primary results of clinical trial for uniform multidrug therapy for leprosy patients in Brazil (U-MDT/CT-BR): reactions frequency in multibacillary patients. Lepr Rev. 2012;83(3):308-19.

32. Gunawan $H$, Sasmojo M, Putri HE, Avriyanti E, Hindritiani R, Suwarsa O. Clinical pilot study: clarithromycin efficacy in multibacillary leprosy therapy. Int J mycobacteriology. 2018;7(2):152-5.

33. Jadhav VH, Patki AH, Mehta JM. Comparison of two multidrug regimens in multibacillary leprosy. Indian J Lepr. 1992;64(4):501-4.

34. Maghanoy AB, M.; Saunderson, P.; Scheelbeek, P. . A prospective randomized, double blind, placebo controlled trial on effect of extended clofazimine on erythema nodosum (ENL) in multibacillary (MB) leprosy. Lepr Rev 2017(88):208-216.

35. Penna GO, Buhrer-Sekula S, Kerr LRS, Stefani MMA, Rodrigues LC, de Araujo $M G$, et al. Uniform multidrug therapy for leprosy patients in Brazil (U-MDT/ CT-BR): results of an open label, randomized and controlled clinical trial, among multibacillary patients. PLoS Negl Trop Dis. 2017;11(7):e0005725.

36. Sampoonachot P, Bundit C, Kuhacharoen N, Peerapakorn S, Kampirapap K, Poomlek $A$, et al. Ofloxacin containing combined drug regimens in the treatment of multibacillary leprosy. Southeast Asian J Trop Med Public Health. 1997;28(4):803-10.

37. Shaw IN, Christian M, Jesudasan K, Kurian N, Rao GS. Effectiveness of multidrug therapy in multibacillary leprosy: a long-term follow-up of 34 multibacillary leprosy patients treated with multidrug regimens till skin smear negativity. Lepr Rev. 2003;74(2):141-7.

38. Cunha Mda G, Virmond M, Schettini AP, Cruz RC, Ura S, Ghuidella C, et al. OFLOXACIN multicentre trial in MB leprosy FUAM-Manaus and ILSL-Bauru. Brazil Leprosy review. 2012;83(3):261-8.

39. Tejasvi T, Khaitan BK, Khanna N, Pandhi RK, Singh MK. Evaluation of a new fixed duration (12 weeks) multi-drug regimen of bactericidal drugs in multibacillary leprosy. Indian J Lepr. 2006;78(4):329-37.

40. Villahermosa LG, Fajardo TT, Jr., Abalos RM, Cellona RV, Balagon MV, Dela Cruz EC, et al. Parallel assessment of 24 monthly doses of rifampin, ofloxacin, and minocycline versus two years of World Health Organization multi-drug therapy for multi-bacillary leprosy. Am J Trop Med and Hyg. 2004;70(2):197-200.

41. Kar HK, Gupta R. Treatment of leprosy. Clin Dermatol. 2015;33(1):55-65.

42. Lockwood DN, Shetty V, Penna GO. Hazards of setting targets to eliminate disease: lessons from the leprosy elimination campaign. BMJ. 2014;348: g1136.

43. WHO. Guidelines for the diagnosis, treatment and prevention of leprosy: Executive Summary. Geneva: World Health Organization; 2018.

44. Ramam M. The continuing relevance of leprosy. JAMA Dermatol. 2019; 155(10):1107-8

45. Kai M, Fafutis-Morris M, Miyamoto Y, Mukai T, Mayorga-Rodriguez J, Rodriguez-Castellanos MA, et al. Mutations in the drug resistancedetermining region of Mycobacterium lepromatosis isolated from leprosy patients in Mexico. J Dermatol. 2016:43(11):1345-9. 
46. Beltran-Alzate C, Lopez Diaz F, Romero-Montoya M, Sakamuri R, Li W, Kimura $\mathrm{M}$, et al. Leprosy drug resistance surveillance in Colombia: the experience of a sentinel country. PLoS Negl Trop Dis. 2016;10(10):e0005041.

47. Saunderson PR. Drug-resistant M leprae. Clin Dermatol. 2016;34(1):79-81.

48. Lavania M, Nigam A, Turankar RP, Singh I, Gupta P, Kumar S, et al. Emergence of primary drug resistance to rifampicin in Mycobacterium leprae strains from leprosy patients in India. Clin Microbiol Infect. 2015; 21(12):e85-6.

49. Avanzi C, Busso P, Benjak A, Loiseau C, Fomba A, Doumbia G, et al. Transmission of drug-resistant leprosy in Guinea-Conakry detected using molecular epidemiological approaches. Clin Infect Dis. 2016;63(11):1482-4.

50. WHO. Global leprosy update. Wkly Epidemiol Rec. 2013;89(36):389-400

51. Tiwari A, Richardus JH. Investment case concepts in leprosy elimination: a systematic review. Lepr Rev. 2016;87(1):2-22.

52. WHO. Global Leprosy Strategy 2016-2020: Accelarating towards a leprosy free-world. World Health Organization; 2016. Available from: http://apps. searo.who.int/PDS_DOCS/B5233.pdf.

53. Chaptini C, Marshman G. Leprosy: a review on elimination, reducing the disease burden, and future research. Lepr Rev. 2015;86(4):307-15.

54. WHO. Enhanced Global Strategy for further reducing the disease burden due to Leprosy. India: World Health Organization; 2009.

55. Gelber R, Andries K, Paredes RM, Andaya CE, Burgos J. The diarylquinoline R207910 is bactericidal against Mycobacterium leprae in mice at low dose and administered intermittently. Antimicrob Agents Chemother. 2009;53(9): 3989-91.

56. Ji B, Chauffour A, Andries K, Jarlier V. Bactericidal activities of R207910 and other newer antimicrobial agents against Mycobacterium leprae in mice. Antimicrob Agents Chemother. 2006;50(4):1558-60.

57. A Study to Evaluate the Efficacy and Safety of Bedaquiline (TMC207) in Participants With Multibacillary Leprosy 2018 [Available from: https:/www. clinicaltrials.gov/ct2/show/NCT03384641?cond=Leprosy\&rank=10.

\section{Publisher's Note}

Springer Nature remains neutral with regard to jurisdictional claims in published maps and institutional affiliations.

Ready to submit your research? Choose BMC and benefit from:

- fast, convenient online submission

- thorough peer review by experienced researchers in your field

- rapid publication on acceptance

- support for research data, including large and complex data types

- gold Open Access which fosters wider collaboration and increased citations

- maximum visibility for your research: over $100 \mathrm{M}$ website views per year

At $\mathrm{BMC}$, research is always in progress.

Learn more biomedcentral.com/submissions 